\title{
OS BENEFícIOS DO E-LEARNING NA ADMINISTRAÇÃO PÚBLICA
}

\author{
THE BENEFITS OF E-LEARNING IN PUBLIC ADMINISTRATION
}

Jullian Hermann Creutzberg ${ }^{1}$

Marco Aurélio Butzke ${ }^{2}$

1

Mestrando em

Administração pela

Universidade do Vale do

Rio dos Sinos - Unisinos

(2016-2018). Tem experiência

na área de Sistemas

de Informação, Gestão

de Pessoas, Governo

Eletrônico, Governo Móvel,

Desenvolvimento de Web

Sites, Aplicativos Web,

Sistemas de Gerenciamento

de Folha de Pagamento e

eSocial. Professor do Curso

de Sistemas de Informação

no Centro Universitário

para o Desenvolvimento

do Alto Vale do Itajaí -

UNIDAVI. Email: jullian@

unidavi.edu.br

2

Possui graduação em

Técnico em Processamento

de Dados pela Fundação

Educacional do Alto Vale

do Itajaí (1990), graduação

em Administração de

Empresas pela Universidade

Para o Desenvolvimento

do Alto Vale do Itajaí

(1996), mestrado em

Mídia e Conhecimento

pela Universidade

Federal de Santa Catarina

(2000) e doutorado em

Administração e Turismo

pela Universidade do Vale

do Itajaí (2015). Atualmente

é professor titular da

Universidade Para o

Desenvolvimento do Alto

Vale do Itajaí e coordenador

do núcleo de informática

da Universidade Para

o Desenvolvimento do

Alto Vale do Itajaí. Email:

marco@unidavi.edu.br
RESUMO: Este artigo apresenta discussões sobre o uso de ferramentas de e-learning no treinamento e desenvolvimento de servidores na administração pública. Através de uma revisão bibliográfica inicialmente apresenta-se uma breve introdução à educação a distância para em seguida ser abordado mais especificamente o $e$-learning. Faz-se também a apresentação da importância do treinamento e desenvolvimento nas organizações, bem como expõe-se de maneira sucinta os aspectos peculiares da administração pública. Acredita-se que toda organização, sendo pública ou privada, necessite de uma estratégia para a capacitação de seus funcionários ou servidores, pois é através disto que se consegue melhorar a qualidade nos serviços prestados à sociedade. Analisando os princípios da administração pública se destaca neste âmbito o princípio da eficiência. A redução de custos se demonstra como um dos principais benefícios do e-learning. Para a estrutura de treinamento e desenvolvimento, algumas das principais vantagens apresentadas são: a maior abrangência, o aumento da produtividade e a disponibilidade dos treinamentos em diversos os horários. Identificar os benefícios que o e-learning pode proporcionar ao desenvolvimento dos servidores públicos, bem como apresentar seus pontos fortes e fracos, ameaças e oportunidades, são formas de instigar a sua utilização e consequentemente contribuir para o desenvolvimento pessoal e profissional das pessoas.

PalaVRas-Chave: e-learning; administração pública; sistemas de informação; gestão de pessoas.

ABstract: This article focuses on discussions about using some tools of e-learning in the training and development of servers in public administration. Firstly, the paper presents a brief introduction to distance education; afterwards, it goes deeper to e-learning. Finally, the paper depicts the importance of training and development in organizations and, also, it shows the peculiar aspects of public administration in a concise way. All organization, public or private, needs some strategies to enable its employees and, thereby, the quality of services offered to community is better. Analyzing the tenet of public administration, the efficiency principle highlights which can be understood as pursuit of quality in public services. The technology of communication brings some benefits to educational methods. One of the major benefits of e-learning is the cost-cutting, as to administration as to society. Some of the main advantages presented for the structure of training and development are: the most comprehensiveness, the increased production and availability of training in several schedules. Identifying the benefits that the e-learning can provide to the public servers development, as well as to present the strengths and weakness, threats and opportunities, are ways to instigate the utilization and consequently contribute people to personal and professional development.

KEYWORDs: e-learning; public administration; information systems; people management. 


\section{INTRODUÇÃO}

As organizações estão compreendendo que as pessoas são essenciais em seu negócio, e estão sendo desafiadas a serem mais ágeis, flexíveis, inovadoras, a operarem com menos recursos e manterem um excelente nível de produtividade.

Desta forma, percebe-se que atualmente uma das áreas mais atuantes em uma estrutura de Recursos Humanos de uma empresa precisa ser a área de Treinamento e Desenvolvimento (T\&D). O treinamento preocupa-se em preparar o funcionário, ou servidor para $\mathrm{o}$ exercício das atividades que serão realizadas, enquanto o desenvolvimento está voltado para o conhecimento, aperfeiçoamento e crescimento profissional.

Não há como ser diferente na administração pública, onde a qualificação do servidor está diretamente relacionada com a qualidade do serviço que será por ele prestado para a sociedade. Percebese a existência de um ciclo, onde o servidor se beneficia recebendo qualificação e adquirindo novos conhecimentos, o que por sua vez, melhora seu desempenho na repartição pública, que é dependente da prestação dos serviços, e consequentemente a sociedade recebe resultados mais satisfatórios.

Segundo Albertin (2001), a tecnologia da informação pode ser definida como uma ferramenta que permite obter, armazenar, tratar, comunicar e disponibilizar informação. Sendo assim, os sistemas de educação a distância, que se utilizam das tecnologias para difusão do conhecimento, se mostram como uma alternativa capaz de trazer inúmeros benefícios para a administração pública.

Com base neste cenário, o presente artigo tem como objetivo principal identificar os benefícios adquiridos no uso de ferramentas de e-learning no Treinamento e Desenvolvimento de servidores na Administração Pública.

Serão apresentados os pontos fortes e oportunidades que o $e$-learning pode oferecer, como também seus pontos fracos e ameaças. Com isto será possível analisar a viabilidade da implantação do mesmo na administração pública como uma ferramenta estratégica para organização, de modo a proporcionar um aumento na produtividade da área de T\&D.

\section{METODOLOGIA}

Este artigo foi fundamentado a partir de uma pesquisa bibliográfica e científica, constituído principalmente de publicações em livros, artigos de periódicos e com conteúdo de sites de organizações públicas e privadas disponibilizados na Internet.

A revisão da literatura envolve a apresentação dos temas centrais do artigo que são o ensino a distância, o e-learning, o treinamento e desenvolvimento nas organizações e a conceituação de administração pública. Para tanto foram consultados autores das áreas de educação, gestão de pessoas, tecnologia da informação e políticas públicas. 
Desta forma é possível a apresentação e a enumeração dos benefícios que o e-learning pode trazer ao treinamento e desenvolvimento de servidores, de forma a aprimorar a prestação de serviços na administração pública.

\section{REVISÃO DA LITERATURA}

\section{A EDUCAÇÃO À DISTÂNCIA}

A educação a distância progride de maneira exponencial à medida que melhora seu conceito diante da sociedade em face aos benefícios que apresenta.

A definição do assunto foi dada pelo Decreto nº 2.494 de 10/02/1998, onde em seu Artigo Primeiro ela é considerada como "uma forma de ensino que possibilita a autoaprendizagem, com mediação de recursos didáticos sistematicamente organizados [...]".

Segundo Guevara e Rosini (2008, p. 173), "cada vez mais, a demanda por educação a distância cresce impulsionada pelos avanços da tecnologia e pela necessidade de o aluno ter seu próprio tempo e ritmo de aprendizagem".

Com a disseminação das tecnologias da Internet, diferentes tipos de aplicativos, foram sendo disponibilizados e aperfeiçoados de modo a apoiar o processo de ensino/aprendizagem dos alunos.

A educação a distância, como proposta alternativa do processo de ensino-aprendizagem, significa pensar em um novo modelo de comunicação capaz de fundamentar e instrumentalizar a estratégia didática. (GUEVARA; ROSINI, 2008, p. 174).

A proposta alternativa de educação a distância ganha força e qualidade a cada dia como uma metodologia eficaz, a ponto de atingir uma grande quantidade de pessoas de maneira mais simples e rápida.

\section{O E-LEARNING}

Como foco do presente estudo, o e-learning ou "ensino pela Internet, é baseado nos modelos de ensino a distância (ou remoto)." (FRANCO, 2001, p.43).

Existem diferentes modelos disponíveis, com diferentes recursos, as modalidades mais utilizadas são: vídeo aulas, módulos com apresentação de slides, acesso a livros, realização de atividades e avalições de forma on-line.

De acordo com Deitel, Deitel e Steinbuhler (2004, p. 269), o e-learning, com o uso da Internet e de tecnologias relacionadas ao desenvolvimento, distribuição e aprimoramento de aprendizado, se apresenta com um enorme potencial e como um novo meio para a educação.

Os autores afirmam ainda que "os especialistas acreditam que este seja o setor da educação de crescimento mais rápido, com previsão para dobrar de tamanho a cada dois anos". 
As vantagens da comunicação instantânea e acessibilidade global através da Internet e a queda dos custos do hardware e das comunicações estimularam o crescimento do e-learning. [...] $\mathrm{O} e$-learning também reduz despesas com viagens, permitindo que as pessoas façam seus cursos no trabalho ou em casa, aumentando a possibilidade de encaixar o aprendizado em suas agendas. (DEITEL; DEITEL; STEINBUHLER, 2004, p. 274).

Embora considerando os grandes avanços recentes das tecnologias, ainda existem algumas dificuldades para seu uso, conforme destacam os autores:

O e-learning depende fortemente de tecnologia e só progredirá com o avanço de tecnologias de banda larga e multimídia [...] As corporações que desejam oferecer programas de e-learning precisarão investir um grande volume de recursos em infraestrutura de tecnologia. (DEITEL; DEITEL; STEINBUHLER, 2004, p. 270).

$\mathrm{O}$ e-learning proporciona ferramentas para o treinamento e o desenvolvimento profissional de funcionários de uma organização através da Internet e facilita o acesso à informação e ao conhecimento.

Segundo Franco (2001, p.43), um dos aspectos importantes do seu uso, particularmente estratégico para o Brasil, é a possibilidade do aumento da produtividade das redes de ensino, através de um melhor gerenciamento e um melhor uso da infraestrutura e dos recursos humanos. O autor destaca ainda que, "os resultados poderão ser largamente multiplicados, ainda, com significativa economia, pois um público maior poderá ser beneficiado, reduzindo o custo unitário por hora/aula/aluno".

\section{O TREINAMENTO E DESENVOLVIMENTO NAS ORGANIZAÇÕES}

Enquanto as organizações sofrem continuamente com profundas transformações nos métodos de gestão de pessoas, também as necessidades das empresas mudam. Atualmente os profissionais necessitam, além das habilidades técnicas, habilidades comportamentais.

Conforme Mascarenhas e Vasconcelos (p. 81, 2006), dentro de uma organização a área de Recursos Humanos (RH) pode ser descrita como uma equipe que desempenha atividades relacionadas a diversos tipos de processos que envolvam o quadro funcional.

E, se tratando da área de RH, é necessário pensar em como gerenciar ou administrar pessoas. Nesta ótica, Araújo (2008, p. 91) destaca que: "vale refletir como o treinamento e o desenvolvimento estão inseridos nesses novos tempos de competição diária pelo melhor posicionamento no mercado".

Normalmente as organizações possuem dentro da estrutura de Recursos Humanos um setor específico para coordenar as atividades de treinamento e desenvolvimento. De acordo com Araújo (2008, p. 
92) esta área "foi criada com o intuito de que as pessoas da organização pudessem ser mais bem capacitadas e ocupar determinadas posições na organização e/ou desenvolver seu potencial à posição ocupada".

Araújo (2008, p. 102) ainda destaca que "é possível afirmar com segurança que T\&D vai experimentar alterações marcantes no campo da transmissão e internalização de conhecimentos com o avanço tecnológico que está sendo produzido pela área da informática".

Em T\&D a alternativa virtual ainda não pode ser considerada uma prática da empresa brasileira, contudo, vale citar a existência de alguns sites que oferecem cursos de extensão, cursos técnicos, cursos de capacitação, especialização, entre outros visando ao treinamento e desenvolvimento. (ARAUJO, 2008, p.101).

A área de T\&D possui também a responsabilidade de proporcionar "o desenvolvimento de carreira, como parte da função do treinamento, deve preparar funcionários para progredir, assumindo cargos em que suas capacidades tenham a máxima utilização possível." (BOHLANDER; SNELL; SHERMAN, 2003, p.31).

O objetivo do treinamento é contribuir para a realização das metas gerais da empresa. Com isso em mente é que os programas devem ser desenvolvidos. Os gerentes devem manter-se atentos às metas e estratégias da empresa e orientar o treinamento de acordo com elas. (BOHLANDER; SNELL; SHERMAN, 2003, p.135).

Conforme destaca Behmer (2002), é importante definir claramente quais são os conhecimentos, habilidades e atitudes que precisam ser desenvolvidos. Contudo, percebe-se a necessidade da atuação efetiva da área de T\&D na estrutura de Recursos Humanos das organizações, porém desde que seja de forma sistemática, planejada e que venha ao encontro das necessidades de cada função ou cargo e dos objetivos da empresa.

\section{A ADMINISTRAÇÃO PÚBLICA}

A Administração Pública pode ser entendida como "o conjunto de órgãos do Estado encarregado de exercer, em benefício do bem comum, funções previstas na Constituição e nas leis". (MEIRELles; 1999, p. 118).

Ela deve obedecer aos princípios previstos no caput do artigo 37, da Carta Magna:

Art. 37. A administração pública direta e indireta de qualquer dos Poderes da União, Estados, do Distrito Federal e dos Municípios obedecerá aos princípios de legalidade, impessoalidade, moralidade, publicidade e eficiência [...] (redação dada pela Emenda Constitucional noำ 19, de 1998). 
3

Análise swot ou Análise FOFA (em português) é uma ferramenta utilizada para fazer análise de cenários, técnica creditada a Albert S. Humphrey (1926 - 2005) sigla de Strenghts (Pontos Fortes), Weaknesses (Pontos Fracos), Opportunities (Oportunidades) e Threats (Ameaças).
Entre os princípios constitucionais cabe destacar o princípio da eficiência. Segundo Reiter e Roveri (2011, p. 12):

O Princípio da Eficiência pode ser entendido como a busca da qualidade no serviço público. E essa busca deve ser sempre direcionada no sentido de proporcionar o melhor para os usuários, e ainda a mais eficaz estrutura administrativa, sempre com vistas ao melhor uso dos recursos públicos.

Pode-se dizer que este princípio possui algumas características básicas: direcionamento da atividade e dos serviços públicos à efetividade do bem comum, imparcialidade, neutralidade, transparência, participação e aproximação dos serviços públicos da população, eficácia, desburocratização e busca de qualidade. (MORAEs; 2007, p. 779 apud VALENTIN; WEEGE; 2011, p.59).

O princípio da eficiência prega tanto para o gestor público, quanto aos seus servidores e ocupantes de cargos eletivos que estes têm o dever de aplicar o dinheiro público de forma eficaz e responsável.

\section{OS BENEFícIOS DO E-LEARNING NA ADMINISTRAÇÃO PÚBLICA}

Atualmente a tecnologia da informação é indispensável às pessoas e às organizações. E a Internet, além de estar voltada ao entretenimento, está também presente na área da educação, com métodos educacionais práticos e eficientes.

Com o tempo o conceito de ensino a distância foi desenvolvido, de tal forma que os estudantes tenham um ambiente virtual para aprendizagem, proporcionando uma maior oportunidade de estudo às pessoas que não têm muitos horários disponíveis. De um lado, o aluno pode estabelecer seu próprio horário, em contrapartida exige maior dedicação e interesse.

Sendo assim, tanto para organizações públicas ou privadas, o ensino a distância pode ser utilizado como estratégia para a capacitação de funcionários de forma mais eficiente.

$\mathrm{O}$ e-learning como meio de ensino-aprendizagem on-line, ganha espaço em diversas organizações e como a maioria dos serviços disponíveis neste formato, torna-se possível a utilização de ferramentas de treinamento mais práticas e abrangentes. Entre as facilidades que acompanham este serviço, podemos citar também a flexibilidade nos horários de estudo para o aluno, que pode aprender em casa ou no local de trabalho, o que reduz os gastos com viagens.

Contudo, em alguns pontos há necessidade de aperfeiçoamento do e-learning por se tratar de um sistema que também envolve o desenvolvimento de tecnologias. Estes dados podem ser melhores analisados a partir do QUADRo a seguir que apresenta uma Análise swot $^{3}$ feita do sistema e-learning. 
QUADRO 1 - Análise SWOT do E-learning.

\begin{tabular}{|c|c|}
\hline \multicolumn{2}{|r|}{ ANÁLISE SWOT DO E-LEARNING } \\
\hline PONTOS FORTES & $\begin{array}{l}\text { - Capacidade de oferecer instrução a um grande número } \\
\text { de estudantes em locais distantes; } \\
\text { - Custos menores (viagens, honorários de professores); } \\
\text { - Cursos mais curtos significam um comprometimento menor } \\
\text { do tempo dos alunos corporativos; } \\
\text { - Custos menores tornam a educação mais acessível } \\
\text { para pessoas com recursos financeiros limitados; }\end{array}$ \\
\hline PONTOS FRACOS & $\begin{array}{l}\text { - Necessidade de grande comprometimento com investimento } \\
\text { em tecnologia por parte das universidades e corporações } \\
\text { que oferecem e-learning; } \\
\text { - Falta de contato pessoal com os alunos; } \\
\text { - A tecnologia atual precisa desenvolver-se mais para su- } \\
\text { portar a interação do aluno-professor barata, sincronizada, } \\
\text { por banda larga. }\end{array}$ \\
\hline OPORTUNIDADES & $\begin{array}{l}\text { - Capacidade de levar instantaneamente ao mundo as novida- } \\
\text { des e tecnologias mais recentes; } \\
\text { - Capacidade de instruir forças de vendas e funcionários } \\
\text { sobre os avanços em produtos; } \\
\text { - Acesso a cursos de diversas universidades; } \\
\text { - Reduz despesas com educação de longo prazo transferindo } \\
\text { programas de aprendizado Web. }\end{array}$ \\
\hline AMEAÇAS & $\begin{array}{l}\text { - Falta de interesse por parte do aluno; } \\
\text { - Requisitos de equipamento e tecnologia limitam a adoção } \\
\text { de e-learning; } \\
\text { - Falta de interação humana prejudica o processo } \\
\text { de aprendizado; } \\
\text { - A maioria dos cursos administrados por instrutores dura } \\
\text { de quatro a cinco dias, um curso mais curto pode deixar } \\
\text { de cobrir alguns tópicos em detalhes. }\end{array}$ \\
\hline
\end{tabular}

FONTE: Adaptado de DeITEL; Deitel; STEINBUhler (2004, p. 269).

Assim, pode-se notar que o e-learning possui algumas deficiências, sendo perceptível a necessidade de maior desenvolvimento tecnológico. Além disso, como citado no QUADro 1, o interesse e dedicação do aluno são fundamentais.

Embora que em qualquer ambiente de aprendizagem o interesse do aluno é importante, obviamente que neste caso é preciso um pouco mais, portanto o aluno deve estabelecer seus horários, reservar tempo para os estudos e, necessariamente precisa buscar informações constantemente.

A falta de interação entre o aluno e o professor também é citada como uma ameaça, e para solucionar este problema, podemos delinear 
as seguintes medidas: a necessidade de despertar o interesse do aluno, a competência dos profissionais selecionados, a qualidade do material disponibilizado e a identificação de estratégias que auxiliem na aprendizagem e adaptação.

Por ser um sistema relativamente novo, se comparado com o ensino presencial, é necessário que o aluno desenvolva suas estratégias de estudo, para se adaptar, organizar seus horários, suas atividades, enfim, com o ambiente de aprendizagem em si.

Em uma estrutura de Recursos Humanos na Administração Pública, a área de T\&D tem como principal função a de proporcionar o treinamento e desenvolvimento dos servidores, porém estas atividades distintas possuem uma estreita ligação conforme apresentado por Araújo (2008, p. 94) o Treinamento e o Desenvolvimento envolvem processo de aprendizagem, porém o primeiro está voltado para o condicionamento da pessoa e para a execução de tarefas e o segundo ao crescimento da pessoa em nível de conhecimento, habilidade e atitude.

Percebe-se que o treinamento e o desenvolvimento são envolvidos com o processo de aprendizagem, ou seja, são responsáveis pela preparação e capacitação das pessoas. Seu objetivo é melhorar o desempenho de cada um, beneficiando não somente o órgão público, mas também o servidor como cidadão, pela oportunidade de adquirir novos conhecimentos e poder crescer profissionalmente. Também para a sociedade que poderá usufruir de um serviço prestado com mais qualidade.

Neste sentido, quanto maiores forem as melhorias feitas no processo de Treinamento e Desenvolvimento, mais qualidade haverá nos serviços prestados pela repartição, refletindo de forma positiva na sociedade e consequentemente no conhecimento e crescimento profissional destes servidores.

Com base nas informações apresentadas, podemos enumerar uma lista contendo os principais benefícios do uso de ferramentas de e-learning na Administração Pública, bem como para a área de T\&D, para os próprios servidores e para a sociedade como um todo.

QUADRO 2 - Principais benefícios do uso de ferramentas de e-learning na Administração Pública.

\begin{tabular}{|l|l|}
\hline \multicolumn{2}{|c|}{ BENEFÍCIOS DO USO DE FERRAMENTAS DE E-LEARNING } \\
\hline & $\begin{array}{l}\text { I. Economia de recursos: gastos com deslocamentos } \\
\text { praticamente reduzidos a zero; menos gastos com } \\
\text { instrutores e professores; possibilidade de atingir } \\
\text { mais pessoas com o mesmo investimento; }\end{array}$ \\
$\begin{array}{l}\text { BENEFícIOS PARA } \\
\text { A ÁnMINISTRAÇÃo }\end{array}$ & $\begin{array}{l}\text { II. Manutenção do conhecimento: com a criação de material } \\
\text { próprio, o conhecimento e a experiência dos servidores } \\
\text { servem como base para o treinamento de novas pessoas; }\end{array}$ \\
& $\begin{array}{l}\text { III. Quadro de pessoal qualificado: além dos profissionais } \\
\text { mais capacitados e qualificados, a administração } \\
\text { colabora com a inclusão social dos servidores; }\end{array}$ \\
\hline
\end{tabular}




\begin{tabular}{|c|c|}
\hline & $\begin{array}{l}\text { Iv. Quadro de pessoal qualificado: além dos profissionais } \\
\text { mais capacitados e qualificados, a administração } \\
\text { colabora com a inclusão social dos servidores; } \\
\text { v. Qualidade nos serviços prestados: proporcionando } \\
\text { o treinamento contínuo e consequentemente o } \\
\text { desenvolvimento dos servidores, a administração } \\
\text { tem a possibilidade de prestar os serviços } \\
\text { com mais qualidade à sociedade. }\end{array}$ \\
\hline $\begin{array}{l}\text { BENEFÍCIOS PARA } \\
\text { A ÁREA DE T\&D }\end{array}$ & $\begin{array}{l}\text { I. Atualização rápida: com o uso de e-learning } \\
\text { se torna mais fácil realizar atualização de } \\
\text { conteúdos e divulgá-los aos participantes; } \\
\text { II. Criação de material próprio: percebe-se a possibilidade, } \\
\text { a partir da compra ou desenvolvimento de uma ferramenta } \\
\text { para cursos on-line, dos próprios servidores criarem módulos } \\
\text { de treinamento que venham ao encontro das necessidades } \\
\text { de cada cargo ou atividade a ser desempenhada; } \\
\text { III. Economia de recursos: geralmente as áreas de t\&D } \\
\text { trabalham com recursos limitados, e com o uso de } \\
\text { ferramentas e-learning, há possibilidade de atingir mais } \\
\text { servidores com a mesma quantidade de investimento, } \\
\text { levando em consideração que em sua grande maioria não } \\
\text { há limitação de quantidade de alunos nas turmas, bem } \\
\text { como não há gastos com deslocamentos e hospedagens; } \\
\text { Iv. Logística simplificada: com o uso de educação a } \\
\text { distância a logística de preparação é extremamente reduzida; } \\
\text { v. Maior abrangência: possibilidade de } \\
\text { disponibilizar os treinamentos para mais servidores } \\
\text { com praticamente o mesmo investimento; } \\
\text { em qualquer computador com acesso à Internet, onde } \\
\text { cada um pode se adaptar para a sua participação. } \\
\text { vir. Qualidade de conteúdo: são inúmeros os exemplos } \\
\text { de órgãos, universidades ou instituições do país que } \\
\text { oferecem treinamentos on-line com conteúdos de } \\
\text { excelente qualidade e constantemente atualizados; } \\
\text { aumentados, pois há possibilidade de ofertar os } \\
\text { cursos e treinamentos para mais servidores; } \\
\text { ficam à disposição de maneira mais rápida e completa; } \\
\text { distros de desempenho e }\end{array}$ \\
\hline $\begin{array}{l}\text { BENEFÍCIOS PARA } \\
\text { OS SERVIDORES } \\
\text { PÚBLICOS }\end{array}$ & $\begin{array}{l}\text { I. Democracia: muitos treinamentos que envolvem } \\
\text { servidores de diferentes idades, culturas, etc., } \\
\text { o ensino a distância permite a participação } \\
\text { de todos sem que se sintam deslocados; }\end{array}$ \\
\hline
\end{tabular}




\begin{tabular}{|c|c|}
\hline & 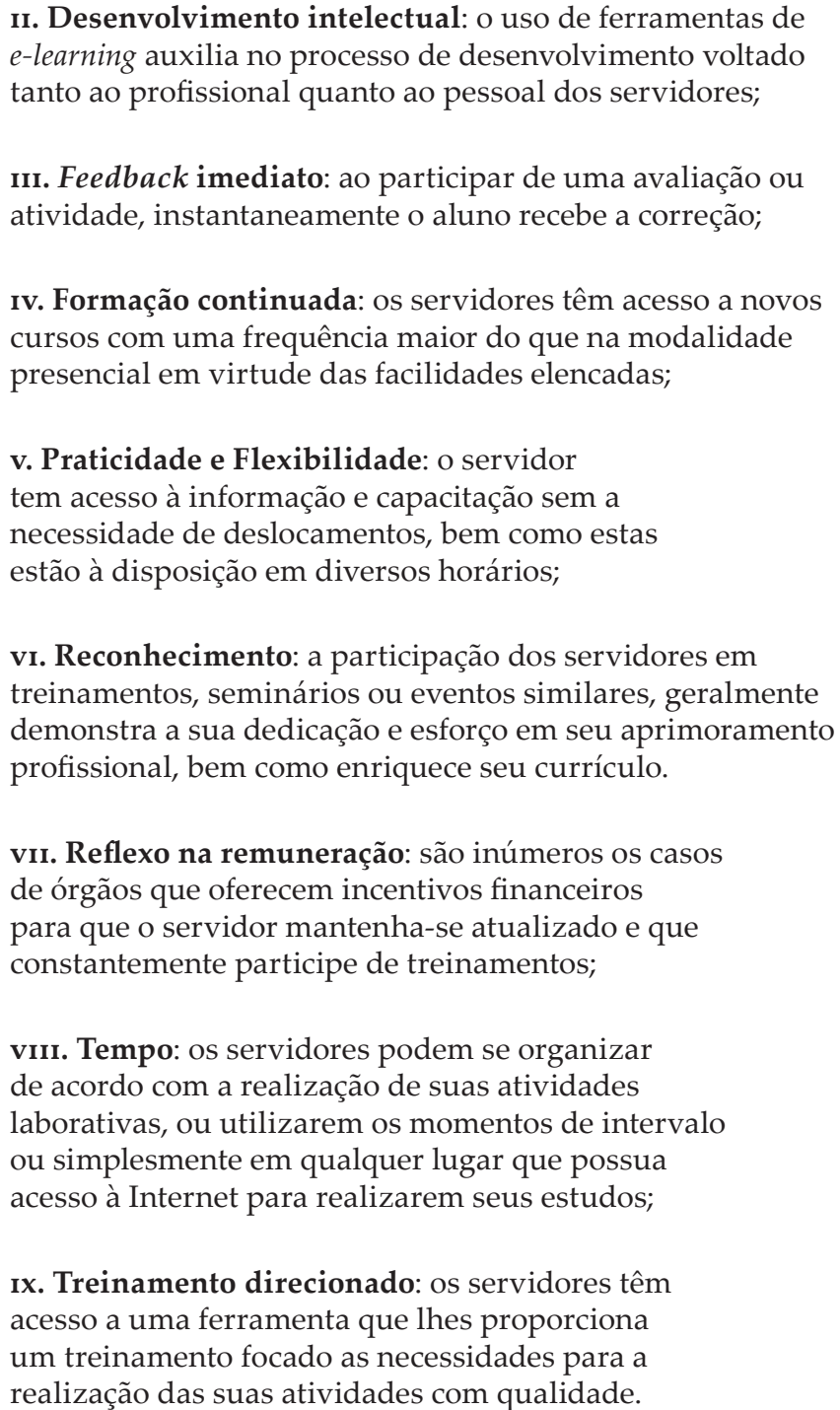 \\
\hline $\begin{array}{l}\text { BENEFÍCIOS PARA } \\
\text { A SOCIEDADE }\end{array}$ & $\begin{array}{l}\text { I. Disponibilidade: sem a necessidade de } \\
\text { grandes deslocamentos, consequentemente os } \\
\text { servidores ficam mais tempo à disposição para } \\
\text { a realização de suas atividades diárias; } \\
\text { II. Economia: por todas as situações elencadas, } \\
\text { e levando em consideração que a sociedade é a } \\
\text { responsável pela manutenção do poder público através } \\
\text { principalmente dos impostos, os recursos economizados } \\
\text { podem ser investidos de diferentes maneiras; } \\
\text { III. Qualidade nos serviços prestados: consequentemente } \\
\text { com um maior aperfeiçoamento dos servidores } \\
\text { públicos, a sociedade recebe um serviço prestado com } \\
\text { uma maior qualidade, gerando maior satisfação; } \\
\text { Iv. Treinamento externo: módulos podem oferecer } \\
\text { treinamento aos cidadãos, mostrando e ensinando } \\
\text { o funcionamento dos procedimentos internos. }\end{array}$ \\
\hline
\end{tabular}

FONTE: Acervo do Autor. 
$\mathrm{O} e$-learning pode auxiliar na melhoria dos processos de T\&D, pois a partir dele é possível criar um sistema mais eficiente e rápido. Com ferramentas deste tipo podem ser realizadas atividades, tais como capacitação dos servidores, desenvolvimento de estratégias para realização de metas, dentre outras, com maior praticidade.

Como estratégias para maximizar os níveis de aprendizagem e, a fim de garantir maior envolvimento e participação dos servidores nos cursos oferecidos, a administração pode ainda proporcionar a destinação de uma carga horária semanal para a dedicação e a realização de cursos de capacitação através de ambientes virtuais, no próprio ambiente de trabalho ou em um local reservado e preparado pela área de T\&D para tal finalidade.

A administração pode ainda, proporcionar a formação de turmas com tutoria presencial, com a adequação de uma sala informatizada e a elaboração de um calendário de aulas conforme carga horária prevista no curso. Ou simplesmente proporcionar um ambiente com computadores com acesso à Internet, onde conforme a disponibilidade de tempo o servidor pode se dedicar a participação nos cursos disponibilizados através dos ambientes virtuais.

Fica muito evidente a expansão pela qual passa o $e$-learning e inúmeras empresas têm investido fortemente nestas plataformas, conforme pesquisa no endereço eletrônico das seguintes organizações: IBM, Intel, Rotary International, Nestlé, Microsoft, Fundação Getúlio Vargas, dentre outras. Pode-se citar ainda um excelente exemplo da área pública: a Escola Nacional de Administração Pública (ENAP), que oferece diversos cursos on-line gratuitamente para órgãos públicos de todo o país.

Com base na literatura de Deitel, Deitel e Steinbuhler (2004, p. 271), sobre integrar o ensino e a Web, "os benefícios são inquestionáveis". Os autores destacam ainda que um treinamento corporativo conduzido presencialmente por instrutor possui uma duração média de quatro a cinco dias o que "representa um comprometimento significativo de recursos para uma empresa, incluindo perda de produtividade por um grupo de funcionários por um longo período".

\section{CONSIDERAÇÕES FINAIS}

A partir do estudo realizado, foi possível compreender o sistema e-learning, seus benefícios e deficiências. Percebeu-se então, que as deficiências citadas, podem ser resolvidas, ou no mínimo amenizadas, e que seus benefícios são realmente notáveis.

O e-learning é um sistema eficiente, que apresenta oportunidades de qualificação para os profissionais da área pública de modo mais abrangente. De acordo com Deitel, Deitel e Steinbuhler (2004, p. 272), as vantagens da comunicação instantânea e acessibilidade global através da Internet, bem como a queda nos custos dos equipamentos e das comunicações estimularam o crescimento do e-learning.

RUIC (2012) publicou na versão eletrônica da Revista Exame uma reportagem apresentando um site que reúne dezenas de vídeoaulas 
de instituições renomadas como Harvard e Massaschusetts Institut of Technology (міт) e também a Universidade de São Paulo (USP). A reportagem destaca ainda que, além de ter acesso gratuito, todo o conteúdo exibido no portal está, aos poucos, sendo legendado para o português.

Notou-se, através do presente artigo, a importância das ferramentas de e-learning para a administração pública na área de T\&D, bem como para o servidor público e para a sociedade. Sendo assim, pode-se concluir que as melhorias que ocorrem no treinamento de pessoas são relevantes e promovem a qualificação e efetividade de todo órgão.

Destaca Deitel, Deitel e Steinbuhler (2004, p. 271), que "é improvável que o treinamento com base na Web torne o método tradicional conduzido por um instrutor obsoleto, mas oferecerá às corporações, universidades e estudantes uma alternativa valiosa de menor custo". Todavia com o e-learning, o servidor pode escolher o melhor momento para dedicar-se aos estudos, não prejudicando o andamento das atividades laborais.

Conclui-se que o uso de ferramentas de e-learning ocasiona avanços para o setor de T\&D, conforme ressalta Araújo (2008, p. 105) sobre os sistemas de educação a distância, "os gestores de pessoas devem estar preparados para utilizar essa nova ferramenta que chegou e vai ficar", pois com elas é possível atingir um maior número de pessoas com menos recursos. Elas também proporcionam aos servidores acesso ao conhecimento para a realização de suas atividades com mais eficiência e eficácia, bem como contribui em seu desenvolvimento pessoal e profissional, aprimorando a qualidade dos serviços prestados.

Contudo, foi possível identificar inúmeros benefícios da aplicação de ferramentas e-learning para o treinamento e desenvolvimento de servidores na administração pública, bem como elencar estratégias que visem maximizar os níveis de aprendizagem dos participantes.

\section{REFERÊNCIAS}

ALBERTIN, A. Comércio eletrônico: modelo, aspectos e contribuiçõoes de sua aplicação. São Paulo: Atlas, 2001.

ARAÚJO, Luis César G. de. Gestão de pessoas: estratégias e integração organizacional. São Paulo: Atlas, 2008. 428 p.

BEHMER, Sara Isabel. O processo de treinamento. In: BOOG, Gustavo; BOOG Magdalena. Manual de gestão de pessoas e equipes. São Paulo: Gente, 2002.

BOHLANDER, George; SNELL, Scott; SHERMAN, Arthur. Administração de Recursos Humanos. São Paulo: Pioneira Thomson Learning, 2003. 547 p. 
BRASIL. Constituição. Emenda Constitucional no ${ }^{0}$ 19, de 4 de junho de 1998. Modifica o regime e dispõe sobre princípios e normas da Administração Pública, servidores e agentes políticos, controle de despesas e finanças públicas e custeio de atividades a cargo do distrito federal, e dá outras providências. Disponível em: <http://www.planalto.gov.br/ccivil_03/ constituicao/Emendas/Emc/emc19.htm> Acesso em: 30.ago.2016. . Ministério da Educação. Decreto n. ${ }^{0}$ 2.494, de 10 de fevereiro de 1998. Brasília: Secretaria de Educação Superior. Disponível em: <http://portal.mec.gov.br/seed/arquivos/ pdf/tvescola/leis/D2494.pdf $>$ Acesso em: 28.ago.2016.

DEITEL, H. M.; DEITEL, P. J.; STEINBUHLER, K. E-business e e-commerce para administradores. São Paulo: Pearson Education do Brasil, 2004.

ESCOLA NACIONAL DE ADMINISTRAÇÃO PÚBLICA (ENAP). Escola Virtual ENAP. Disponível em: < http://www. enap.gov.br/pt/web/pt-br/a-distancia> Acesso em: 30.ago.2016.

FÁVERI, Helena Justen de, BLOGOSLAWSKI, Ilson Paulo Ramos, FACHINI, Olimpio. Educar para a Pesquisa: Normas para Produção de Textos Científicos. $3^{\underline{a}}$ Ed. Nova Letra, 2008.

FRANCO JR., Carlos F. E-business: tecnologia da informação e negócios na Internet. São Paulo: Atlas, 2001. 281 p.

FUNDAÇÃO GETÚLIO VARGAS (FGV). FGV On-

line. Disponível em: <http://www5.fgv.br/fgvonline/

Cursos/Gratuitos/> Acesso em: 30.ago.2016

GRUPO A EDUCAÇÃO. Case Nestlé evidencia os

benefícios do e-learning. Disponível em: <http://

gsionline.com.br/penseelearning/case-nestle-evidencia-

os-beneficios-do-e-learning/> Acesso em: 10.jan.2016.

GUEVARA, Arnoldo José de Hoyos; ROSINI, Alessandro

Marco. Tecnologias emergentes: organizações e

educação. São Paulo: Cengage Learning, 2008. 333 p.

IBM. E-Learning IBM. Disponível em: <http://

www-304.ibm.com/jcto3001c/services/ learning/ites. wss/br/pt?pageType $=$ page\&c $=\mathrm{C}_{229571{ }^{2}} 40559 P_{19}>$

Acesso em: 30.ago.2016.

INTEL CORPORATION. Benefícios da Intel® Learning Series para a comunidade. Disponível em: $<$ http://www. intel.com.br/content/www/br/pt/intel-learning-series/ economic-benefits.html> Acesso em: 20.ago.2016. 
MASCARENHAS, André Ofenhejm; VASCONCELOS, Flávio Carvalho de. Tecnologia na Gestão de Pessoas: Estratégias de auto-atendimento para o novo RH. São Paulo: Pioneira Thomson Learning, 2004. 174 p.

MEIRELLES, Hely Lopes. Direito Administrativo

Brasileiro. 24 ed. São Paulo: Malheiros Editores, 1999.

MICROSOFT CORPORATION. Microsoft E-Learning. Disponível em: <http://www.microsoft.com/pt-br/licenciamento/ software-assurance/e-learning.aspx> Acesso em: 30.ago.2016.

REITER, Giovana Mara; ROVERI, Claudia. Normas Práticas das Licitações Públicas e Contratos. Indaial: Uniasselvi, 2011.

ROTARY INTERNATIONAL. E-Learning Center do Rotary. Disponível em: <http:/www.rotary.org/pt/members/training/ forallrotarians/pages/elearning.aspx> Acesso em: 30.ago.2016.

RUIC, Gabriela. Cursos do MIT e de Harvard chegam à web em português. Exame.com. São Paulo, 26.ago.2012. Disponível em: <http://exame.abril.com.br/tecnologia/ noticias/cursos-do-mit-e-de-harvard-chegam-a-web-emportugues?utm_source=newsletter\&utm_medium=e-mail\&utm_ campaign=news-semanal.html $>$ Acesso em: 20.ago.2016.

VALENTIN, Ilda; WEEGE, Sonia Adriana. Organização municipal e Legislação. Indaial: Uniasselvi, 2011. 